\title{
Mulheres imigrantes em Portugal: uma análise de gênero
}

\author{
Immigrant women in Portugal: \\ A gender analysis
}

\author{
Ana Sofia Antunes das NEVES ${ }^{1}$ \\ Maria da Conceição Oliveira Carvalho NOGUEIRA² \\ Joana Bessa TOPA ${ }^{1}$ \\ Estefânia Gonçalves SILVA ${ }^{1}$
}

\section{Resumo}

Este texto procura discutir teoricamente a importância de se analisar as migrações a partir de uma perspectiva de gênero. Tomando como referência uma das mais marcantes características da era atual das migrações, a feminização, aponta-se a necessidade de refletir e questionar os processos e as dinâmicas subjacentes às migrações femininas e às suas características específicas. São apreciados neste texto os contributos das teorias feministas para o entendimento das migrações das mulheres, assim como são observadas as implicações de se considerar as migrações um fenômeno genderizado. São também sistematizados alguns dos estudos sobre mulheres imigrantes realizados em Portugal mais recentemente, mapeando-se as temáticas mais abordadas e os resultados alcançados.

Palavras-chave: Feminismo; Gênero; Migração; Portugal.

\begin{abstract}
This study aims to theoretically discuss the importance of analyzing migrations from a gender perspective. Based on one of the most striking features of migrations in the modern age - the feminization of migrations -, we point out the need to reflect and analyze the processes and dynamics underlying female migration and their specific characteristics. This paper examines the contributions of feminist theories to the understanding of women's migrations and the implications of considering migrations a gendered phenomenon. Some recent studies on immigrant women in Portugal were systematized, mapping the most frequently addressed topics and the results achieved.
\end{abstract}

Keywords: Feminism; Gender; Migration; Portugal.

Na Europa, como no resto do mundo, o número de mulheres migrantes tem aumentado nas últimas décadas, estando na base desta tendência uma cada vez mais notória procura de autonomização por parte do sexo feminino (Gabaccia, 1992). Se outrora as mulheres migravam, sobretudo,

\footnotetext{
1 Instituto Universitário da Maia, Departamento de Ciências Sociais e do Comportamento. Av. Carlos Oliveira Campos, Castêlo da Maia, 4475-690, Avioso S. Pedro, Portugal. Correspondência para/Correspondence to: A.S.A. NEVES. E-mail: <d010942@ismai.pt>.

2 Universidade do Porto, Faculdade de Psicologia e Ciências da Educação. Porto, Portugal.
} 
com vista à reunificação familiar (Miranda, 2009), hoje fazem-no também, e muitas vezes, sozinhas e por razões que nada têm a ver com o universo familiar. Um número expressivo de mulheres migra hoje no encalço de melhores condições de vida, tentando esbater estatutos de menoridade social e escapar à discriminação, ao preconceito e à opressão a que estão expostas nos seus países de origem (Morokvasic, 1984; United Nations Development Fund for Women, 2003, 2006).

O interesse em analisar e compreender as dinâmicas migratórias tem feito proliferar, nas últimas décadas, no domínio das Ciências Sociais e Humanas, um vasto conjunto de estudos empíricos e de reflexões teóricas (Boyle \& Halfacree, 1999). O aumento da participação das mulheres nos fluxos migratórios internacionais é uma das questões que mais têm sido colocadas no âmbito das teorias sobre as migrações (Assis, 2007), constituindo-se a feminização como um dos aspectos mais relevantes sobre as migrações da atualidade (Castles \& Miller, 2003).

A crescente (ou pelo menos mais visível) feminização das migrações, fenômeno também designado por genderização (Yamanaka \& Piper, 2006), tem impulsionado, na realidade, uma mudança de paradigma nos estudos sobre o assunto, obrigando a adoção de uma perspectiva teórica e empírica mais inclusiva, no seio da qual se considera a influência das questões de gênero e da interseccionalidade nas dinâmicas migratórias (Bhavnani, 1997; Crenshaw, 1991; Morokvasic, 1984). Até os anos 1970, o estudo das migrações não era realizado a partir de uma matriz de gênero, muito menos interseccional, diluindo-se as particularidades das migrações femininas na observação das dinâmicas e dos processos migratórios masculinos (Assis, 2003). A partir dos anos 1970, no entanto, as questões de gênero começaram a ser paulatinamente colocadas na agenda dos estudos migratórios, os quais foram revitalizados pelas pesquisas étnicas e pelo desenvolvimento dos estudos feministas (Assis, 2003). Na realidade, o interesse pelo estudo do gênero nas migrações surgiu quando do estabelecimento dos Estudos sobre as Mulheres nas décadas de 1970 e 1980 (Lutz, 2010), período que coincidiu precisamente com o desenvolvimento da teoria feminista
A análise do gênero como categoria analítica das migrações ou surgia, até aí, nas investigações em segundo plano (Gonçalves \& Figueiredo, 2005) ou não era sequer considerada. Até muito recentemente, o papel das mulheres nas migrações e na complexa rede de relações sociais que as suportam estava obscurecido, tendo sido tardiamente incluído nas teorias gerais das migrações (Assis, 2003). De acordo com Morokvasic (1984), as mulheres foram, durante muito tempo, vistas como dependentes passivas, limitando-se a seguir ou a acompanhar as aspirações dos homens imigrantes, seus companheiros ou familiares. Por isso mesmo, as mulheres têm permanecido mais ou menos invisíveis na pesquisa e na investigação sobre as migrações, o que acompanha, aliás, uma tendência clássica de exclusão do sexo feminino da ciência (Gill, 2006; Hollway, 1989; Neves, 2009; Sherif, 1987).

Nolin (2006), alegando que as migrações são, em si mesmas, processos genderizados, discute a impossibilidade de se desenvolverem estudos sobre o assunto sem que se contemplem forçosamente as questões de gênero. Seguindo essa premissa, considera-se que ao excluir a dimensão de gênero das investigações sobre as migrações e as suas dinâmicas fomenta-se um estado de cegueira o qual tem como efeito a perpetuação de uma visão de neutralidade, que efetivamente não existe (Willis \& Yeoh, 2000). Embora gradualmente se assista a um aumento de estudos no domínio das migrações femininas, nem sempre estas são, como já dito anteriormente, observadas a partir de uma matriz de gênero. Na realidade, muitas das pesquisas que se intitulam como de gênero, nesse domínio, não o são de fato, já que se limitam a tomar o gênero como uma variável, desprovido da sua significação política (Neves, 2011).

Refletindo sobre a ausência das mulheres nos estudos teóricos e empíricos sobre migrações e apoiando-se nas considerações de outros autores e autoras, Lutz (2010) enuncia quatro tipos de razões explicativas: 1) a ordem de gênero dominante dos séculos XIX e XX ditou que o enfoque nos homens fosse considerado natural, não atendendo a uma realidade que efetivamente contrariava o argumento de que apenas os homens migravam; 2) a 
escassez de investigadoras e teóricas feministas na área fez com que se produzisse muito pouco sobre as experiências das mulheres no âmbito das migrações. Segundo a autora, o sexo de quem produz conhecimento influencia a escolha do objeto e do sujeito estudados; 3) o fato das mulheres serem perspectivadas como seguidoras dos homens, menorizou o seu estatuto nos processos migratórios. Por outro lado, a imigração feminina autônoma era considerada uma bizarria, sobre a qual não fazia sentido teorizar; 4) finalmente, a própria modernidade e as configurações dela decorrentes, explicam o pouco interesse em estudar as mulheres migrantes. Por não ocuparem tendencialmente lugares sociais valoráveis (conotados como verdadeiro trabalho), as mulheres foram relegadas para segundo plano na análise das migrações. Os estudos feministas têm, no entanto, favorecido uma gradual descentração desse modelo dominante, evidenciando, nos últimos anos, as implicações do gênero, mas também de outros eixos de análise, nas dinâmicas migratórias (Kofman, Sales, Phizucklea, \& Raghuran, 2000).

Hess e Ferree (1987) enunciaram a existência de três marcos de pesquisa feminista relacionada com as migrações, os quais assinalam a evolução dos estudos de gênero nesse domínio. O primeiro marco caracteriza-se por uma tentativa de remediar a exclusão das mulheres na investigação científica e pode ser situado entre 1970 e 1980. Denominada de "mulheres e migração", essa fase procurou promover análises para além da dimensão da reunificação familiar, entendida classicamente como a motivação central na base da imigração feminina. Os estudos realizados nesse período atestam a importância de se explorar com mais detalhe o papel das mulheres nas migrações. As suas principais conclusões apontam no sentido das mulheres migrantes, estando mais vinculadas a trabalhos domésticos, serem habitualmente, nos países receptores, remetidas para a esfera do privado, enquanto os homens são mais incentivados a ocupar a esfera pública. $\mathrm{O}$ segundo marco caracteriza-se pelo desenvolvimento de estudos sobre a interligação entre gênero e migrações e assinala a transição dos temas Mulher e Migração para os temas Gênero e Migração. Partindo da associação entre os conceitos de raça, classe e gênero, essas pesquisas basearam-se nos padrões de gênero e na forma como a migração reconfigura os sistemas de igualdade/desigualdade de gênero. O terceiro e último marco de pesquisa feminista relacionada com as migrações, ainda em fase de maturação, caracteriza-se pela assunção do gênero como elemento constitutivo das migrações. Nesses estudos, tem-se dado ênfase nas questões de gênero enquanto fatores responsáveis pela proliferação de certas dinâmicas migratórias favoráveis à discriminação de alguns grupos de mulheres.

De acordo com Lutz (2010), é possível identificar quatro fases no desenvolvimento da investigação sobre migrações e gênero. A primeira, a qual se constitui com a entrada dos movimentos feministas na academia, assinala uma tentativa de dar visibilidade às mulheres, demonstrando os padrões migratórios femininos típicos assim como as características específicas desses processos. Trata-se, do ponto de vista teórico, de uma abordagem compensatória. A segunda fase pode ser apelidada como contributória, já que se caracteriza por procurar demonstrar os contributos das mulheres para os vários movimentos migratórios, em termos da singularidade dos seus papéis e das suas experiências.

A terceira fase, iniciada em meados dos anos 1980 nos Estados Unidos da América e ampliada nos anos 1990, visava sublinhar as diferenças nas relações de poder entre mulheres. Inspirados nos trabalhos de feministas afro-americanas, como Angela Davis ou bell hooks, investigadores negros e imigrantes começaram a pôr em causa as epistemologias dominantes e a recorrente homogeneização do sujeito mulher. Essa fase, denominada de debate raça-classe-gênero, foi altamente politizada, originando algumas fissuras dentro dos próprios movimentos feministas. A quarta fase, despontada em meados dos anos 1990, marca a derradeira transição dos Estudos sobre as Mulheres para os Estudos de Gênero. A partir dessa altura, a assimetria de gênero passou a ser conceitualizada como um produto da ordem social, analisando-se os processos migratórios como uma extensão das relações sociais de gênero.

É reconhecido, no presente, que a compreensão das dinâmicas migratórias só se pode fazer 
considerando as especificidades dos grupos que as protagonizam. A diversidade das experiências das migrantes aponta para a necessidade de uma análise menos essencializada das migrações femininas, já que a categoria mulher é polissêmica e não homogênea. Não só as migrações femininas são diferentes das masculinas, como corporizam uma realidade heterogênea para as próprias mulheres. Ainda assim, nota-se que as diferenças existentes entre homens e mulheres imigrantes são muitas vezes comparadas nas pesquisas, não sendo problematizadas com o intuito de se sistematizar o que as constrói, as condiciona ou as mantêm. As lógicas de poder, as desigualdades delas decorrentes e as condições econômicas dos países de acolhimento e de origem, facilitam o acesso das mulheres imigrantes aos contextos domésticos de trabalho, confinando-as em um papel social marcado pela invisibilidade (King \& Zontini, 2000; United Nations Population Fund, 2006). A feminização das migrações coabita, por isso mesmo, e muitas vezes, com a feminização da pobreza e do trabalho (Boyd, 2006; Silva, Nogueira, \& Neves, 2010).

As experiências migratórias das mulheres estão imbuídas de singularidades, especialmente no que diz respeito às vulnerabilidades que nelas se entrecruzam, em termos de pertença de gênero, mas também de outras pertenças, como as étnicas, de classe, de idade e de orientação sexual (Crenshaw, 1991; Neves, 2010a). Nesse percurso, dos anos 1970 até o presente, as mulheres têm ganhado autonomia, não sendo hoje estudadas apenas como membros dependentes das suas famílias nas trajetórias migratórias. Na realidade, todos os dados apontam para o fato das mulheres serem cada vez mais, na atualidade, atoras econômicas independentes (Garip, Curran, Shafer, \& Donato, 2006).

\section{A investigação científica sobre as migrações femininas em Portugal}

Com diferentes capitais humanos, as mulheres migrantes ocupam hoje uma parcela muito significativa nas estatísticas migratórias nacionais e internacionais, de tal forma que já se assume a repercussão da sua presença em Portugal como um con- tributo inequívoco para a economia do país (Pires, 2002). De abril de 1974 até ao presente, Portugal sofreu mudanças profundas, também no que diz respeito aos seus fluxos migratórios. O regime fascista que dominou o país durante quase 50 anos restringiu a entrada de imigrantes, fazendo proliferar políticas altamente restritivas. Segundo Santos (2004), a visão de Portugal como país de imigração surge apenas no XI Governo Constitucional, depois da entrada do país na Comunidade Econômica Europeia em 1986, consolidando-se a partir do início dos anos 1990. Apesar dessa visão tardia, o número de imigrantes em Portugal tem crescido sistematicamente desde 1975 a uma taxa média anual acima de $7 \%$ (Pires, 2002).

A origem dos fluxos migratórios manteve-se relativamente estabilizada até o fim da década de 1990, sofrendo depois alterações profundas. Entre os finais das décadas de 1970 e de 1990, predominaram os fluxos provenientes do mundo lusófono: africanos vindos dos Países Africanos de Língua Oficial Portuguesa (PALOP) e um contingente estável de brasileiros (Peixoto, 2004). Nas décadas de 1980 e 1990, o número de estrangeiros continuou a aumentar a um ritmo razoável, devendo-se esta evolução à presença de imigrantes africanos e, em simultâneo, à diversificação das origens da população estrangeira, nomeadamente de imigrantes vindos da Europa e do Brasil e de pequenos fluxos da Índia e da China.

Nos anos de 1992/93 e 1996, de forma a regularizar as situações dessas pessoas em Portugal, procederam-se duas campanhas de regularização, verificando-se, dessa forma, que grande parte dos imigrantes em situação de irregularidade era de cidadãos das ex-colônias africanas (Fonseca, Ormond, Malheiros, Patrício, \& Martins, 2005). Durante esse período, Portugal assistiu a dois tipos diferentes de imigração. O primeiro tipo de natureza laboral, muito associado aos PALOP (Pires, 2002), em que se observou o recrutamento de imigrantes para trabalhos nos setores da construção civil, nas obras públicas e em serviços mais desqualificados (Fonseca et al., 2005). E o segundo de natureza profissional, protagonizado em especial por imigrantes de países europeus, mais concretamente provenientes da 
Espanha e do Reino Unido, em que se evidenciou o recrutamento de profissionais altamente qualificados (Wall, Nunes, \& Matias, 2005) para áreas laborais igualmente mais qualificadas (Pires, 2002).

Em uma tentativa de sistematização das movimentações desses agrupamentos humanos para Portugal enquanto país receptor, Malheiros (2000) agrupou os fluxos dos imigrantes em três categorias diferentes. A primeira composta por trabalhadores com baixas qualificações, especialmente vindos dos PALOP. A segunda categoria, formada por trabalhadores da Europa Ocidental, recrutados para setores mais específicos da economia portuguesa. A terceira categoria, constituída por brasileiros, os quais, especialmente nos anos 1980, eram trabalhadores altamente qualificados em setores específicos, como a medicina, e que recentemente têm se inserido em outros setores, nomeadamente, no comercial. Wall et al. (2005) referem ainda uma quarta categoria de fluxos de imigrantes, composta por pessoas oriundas de Moçambique, China e Índia. Estes apresentam qualificações médias e trabalham em setores comerciais.

Com a evolução dos fluxos imigratórios, Portugal tornou-se um país ainda mais multicultural, caracterizado por múltiplas singularidades sociodemográficas. Uma dessas singularidades, importante porque saliente, prende-se com o crescimento contínuo da presença de mulheres imigrantes no país. Muito embora o conhecimento sobre as realidades das mulheres imigrantes em Portugal tenha aumentado, os estudos sobre migrações realizados nos últimos anos no país continuam a ser dispersos e pontuais, não havendo um interesse contínuo e sistematizado pela área por parte dos investigadores (Miranda, 2009). Por outro lado, estes resistem em estabelecer alianças objetivas com as perspectivas de gênero e as grelhas de análise feministas, sendo as investigações sobre migrações com um enfoque de gênero ou feminista francamente escassas.

Ainda assim, é possível identificar, na produção científica portuguesa, uma tentativa de compreensão das imigrações femininas tomando as experiências das mulheres como independentes das dos homens. Essa produção tem sido efetuada especialmente no seio dos centros de investigação sobre migrações e/ou gênero, não havendo ainda uma base de dados nacional que congregue informação sobre os trabalhos realizados nesse domínio. A visibilidade desta produção tem sido conseguida por intermédio do agora Alto Comissariado para as Migrações (ACM) - antes Alto Comissariado para a Imigração e Diálogo Intercultural (ACIDI) que, de modo a colmatar uma lacuna no que toca à edição de dissertações de mestrado e teses de doutoramento sobre imigração e minorias étnicas em Portugal, criou um incentivo à sua publicação, através do Observatório da Imigração. O mesmo organismo patrocina outros estudos, assim como sua publicação, contribuindo para a difusão de informação sobre a imigração feminina em Portugal. Com vista a mapear algumas das produções científicas mais recentes (últimos 5 anos), serão apresentados em seguida alguns dados relativos a investigações publicadas em Portugal sobre mulheres imigrantes pelo ACIDI. Essa apresentação não pretende ser exaustiva, mas apenas pontuar alguns dos trabalhos de referência.

Em 2007 foi publicada a tese "Conhecimentos, atitudes e práticas sobre planeamento familiar de mulheres Timorenses residentes em Portugal", de autoria de Manuel, cujo objetivo foi analisar os conhecimentos, atitudes e práticas relativos ao Planejamento Familiar revelados por mulheres timorenses residentes em Portugal (Manuel, 2007). Concluiu-se, nesse trabalho, entre outros aspectos, que a dimensão cultural, bem como as circunstâncias em que as mulheres timorenses se encontram após terem vindo para Portugal, condicionam suas atitudes sobre a fecundidade.

No mesmo ano, a autora Monteiro (2007) publicou a tese "Ser mãe Hindu: práticas e rituais relativos à maternidade e aos cuidados à criança na cultura Hindu em contexto de imigração". Nesse trabalho, a autora reflete sobre as concepções e as práticas da maternidade, concluindo que a cultura de origem continua a ditar os rituais produzidos nos países receptores.

Também em 2007, Lopes publica a sua tese sobre "Gravidez e seropositividade em mulheres imigrantes na região de Lisboa". A autora explora em seu trabalho as preocupações, dúvidas e dificuldades vividas por um grupo de grávidas seropositivas 
imigrantes, usuárias da Consulta de Obstetrícia de um Hospital da Região de Lisboa. Das conclusões dessa tese, ressalta-se o fato dessas mulheres se sentirem pouco apoiadas no contato com os profissionais de saúde e o fato de revelarem pouca informação sobre o Vírus da Imunodeficiência Humana (HIV) (Lopes, 2007).

Abranches, igualmente em 2007, publica a tese "Pertenças fechadas em espaços abertos: estratégias de (re)construção identitária de mulheres muçulmanas em Portugal", no seio da qual analisa, em uma lógica comparativa, as estratégias específicas de negociação de mulheres muçulmanas de origem guineense e indiana (Abranches, 2007). A autora concluiu haver um forte controle familiar e social sobre essas mulheres, o qual dificulta (embora não iniba) a assimilação de novos elementos socioculturais presentes na sociedade de destino.

Ainda no mesmo ano, Santos publica o trabalho "Imagens de mulheres imigrantes na imprensa portuguesa. Análise do ano 2003", onde analisa a forma como a imprensa portuguesa representa as mulheres imigrantes. A autora concluiu que há um processo de generalização e de estereotipificação das imigrantes, o qual alimenta uma imagem redutora dos seus atributos e competências (Santos, 2007).

Também no mesmo ano, Padilha (2007) concluiu, em um trabalho denominado "A imigrante brasileira em Portugal: considerando o gênero na análise", que a imagem dessas mulheres em Portugal está conotada com o rótulo de prostituta, influenciando negativamente as experiências de migração. Nas palavras da autora "o estereótipo da prostituição também gera uma marca de hostilidade entre as próprias mulheres, brasileiras e portuguesas e, mesmo, nas brasileiras entre si" (p.126). Os trabalhos publicados por Correia e Neves (2010, 2011) vem reforçar essa ideia, salientando um outro aspecto muitas vezes camuflado na investigação: o de que as imigrantes brasileiras são vítimas de violência sexual no contexto do trabalho que exercem como empregadas domésticas.

Em 2009 foi publicado o estudo "Fluxos matrimoniais transnacionais entre brasileiras e portugueses: gênero e imigração", de autoria de Raposo e Togni (2009). Procurou-se, nesse trabalho, analisar os fluxos matrimoniais transnacionais entre brasileiras e portugueses, priorizando-se a ligação entre gênero, nacionalidade e conjugalidade. Dos resultados alcançados, destaca-se a questão da heterogeneidade dos sujeitos envolvidos no fenômeno, a oscilação dos padrões e dos papéis de gênero e a multiplicidade de soluções de integração, assimilação, isolamento e de intercâmbio e diálogo intercultural.

No mesmo ano, Miranda (2009) publicou "Mulheres imigrantes em Portugal: memórias, dificuldades de integração e projetos de vida". A autora analisa, a partir de uma perspectiva de gênero, as memórias, as identidades, as dificuldades de integração em Portugal e os projetos de vida das mulheres imigrantes de nacionalidade brasileira, ucraniana e cabo-verdiana. Das conclusões apontadas, sobressai o fato das ucranianas sentirem mais dificuldade na sua integração, embora as outras duas nacionalidades experimentem também significativos constrangimentos relativos à adaptação em Portugal. No caso das brasileiras, podem ser referenciadas as situações de assédio sexual e o preconceito, no caso das cabo-verdianas o racismo e a discriminação no trabalho.

Também em 2009, foi publicado o estudo "Saúde sexual e reprodutiva de mulheres imigrantes africanas e brasileiras", das autoras Dias, Rocha e Horta. O objetivo desse trabalho foi o de descrever os conhecimentos, atitudes e práticas relativas à saúde sexual e reprodutiva de mulheres imigrantes, analisando a influência dos processos migratórios na saúde sexual e reprodutiva. Foi também um dos propósitos da investigação identificar barreiras e elementos facilitadores no acesso e utilização dos serviços de saúde. Os resultados vão no sentido da heterogeneidade e diversidade das práticas e dos conhecimentos, havendo muitas barreiras no acesso aos serviços de saúde (Dias, Rocha, \& Horta, 2009). O trabalho de Topa, Nogueira e Neves (2010) vem aprofundar a questão da dificuldade das mulheres imigrantes no acesso à saúde, discutindo a necessidade de se reverem as políticas de saúde para migrantes em Portugal. 
Em 2010, foi publicado o estudo "Repertórios femininos em construção num contexto migratório pós-colonial (volumes I e II)", de autoria de Trovão e Ramalho, no qual se procurou compreender as dinâmicas familiares, a vulnerabilidade e a participação cívica de mulheres de origem caboverdiana e são-tomense no contexto pós-colonial português. As autoras concluíram que as participantes foram expostas, durante a socialização, a tradições discursivas e práticas de desigualdade de gênero as quais condicionaram as suas experiências futuras (Trovão e Ramalho, 2010a, 2010b).

Outros estudos portugueses, efetuados nos últimos cinco anos, para além dos publicados pelo ACIDI, são dignos de referência neste texto, dado o seu enfoque de gênero. Destaca-se o trabalho realizado por Wall et al. (2005) que concluíram, no estudo intitulado "Immigrant women in Portugal: Migration trajectories, main problems and policies", que as três nacionalidades mais presentes em Portugal, no que se refere às mulheres imigrantes, são a cabo-verdiana, a brasileira e a ucraniana. As mulheres cabo-verdianas e as ucranianas, segundo dados recolhidos nessa investigação, trabalham, sobretudo, no setor da limpeza e em contextos domésticos, enquanto as brasileiras estão mais afeitas à indústria hoteleira e restauração. Os três grupos têm, no geral, empregos pouco qualificados. As mulheres imigrantes cabo-verdianas, brasileiras e ucranianas estão habitualmente expostas a situações de discriminação e de violência, o que as constrange em termos do acesso a direitos fundamentais e a serviços de apoio e de saúde.

No mesmo ano, 2005, é publicada pelo SOS Racismo a obra "Imigração e etnicidade: vivências e trajetórias de mulheres em Portugal", onde são reunidos vários contributos de investigadores e investigadoras sobre a imigração feminina em Portugal. Os 21 capítulos que compõem a obra clarificam a situação das mulheres imigrantes no país e abrem pistas importantes para a investigação que se seguirá (SOS Racismo, 2005).

Peixoto et al. (2006) apresentaram o Relatório Final do Projeto "Mulheres migrantes: percursos laborais e modos de inserção socioeconômica das imigrantes em Portugal". Buscou-se estudar, nessa pesquisa, o universo das mulheres imigrantes de nacionalidade estrangeira em Portugal, do ponto de vista da inserção no mercado de trabalho, da educação e da formação profissional, das condições familiares e da vida privada, da inserção e grau de centralidade em redes sociais e dos dispositivos jurídicos e políticos relevantes para a condição migrante.

Neves (2010b) discutiu a problemática do tráfico de mulheres para fins de exploração sexual, analisando a relação entre a feminização das migrações e a violência de gênero. Essa relação tem sido cada vez mais documentada em Portugal, sobretudo a partir da publicação de "O tráfico de migrantes em Portugal: perspectivas sociológicas, jurídicas e políticas", de autoria de Peixoto (2005), e do livro "Tráfico de mulheres em Portugal para fins de exploração sexual", coordenado por Santos, Gomes, Duarte e Baganha (2008).

Como se depreende da análise deste mapeamento (saliente-se, não exaustivo) dos estudos realizados em Portugal sobre imigração feminina, as temáticas abordadas são diversas, assim como os enfoques teóricos a partir dos quais as investigações se desenvolvem. As conclusões sugerem, no entanto, que a pertença de gênero (para além de outras pertenças identitárias) afeta os percursos migratórios das mulheres, constrangendo-as muitas vezes a nível pessoal, familiar, social e comunitário.

Constata-se que o argumento enunciado por Lutz (2010), de que o sexo de quem produz investigação científica influencia a escolha do objeto e do sujeito estudado, encontra sustentação em Portugal. Grande parte da investigação produzida é, na realidade, feita por investigadoras mulheres que ora se identificam mais com o domínio dos Estudos sobre Migrações ora com o domínio dos Estudos de Gênero. Das pesquisas aqui descritas, muito poucas se assumem como tendo orientação feminista e nem todos são efetivamente estudos de gênero.

\section{Conclusão}

As mulheres representam, atualmente, uma parcela considerável do universo global da popula- 
ção migrante disseminada pelo mundo. A feminização das migrações resulta de um conjunto de forças estruturais condicionadas pelos papéis de gênero, pela discriminação sexual e pela globalização. As mulheres migram hoje por motivos variados: algumas fazem-no por razões de índole econômica, outras para assegurar a reunificação familiar ou escapar a constrangimentos culturais. No cenário atual de feminização da imigração, as mulheres imigram cada vez mais por sua conta e risco, em busca de emancipação e autonomia pessoal e econômica, não se resignando passivamente perante as múltiplas formas de discriminação de que são alvo, associando-se inclusivamente a outras mulheres com o intuito de chamar a si direitos fundamentais de exercício de cidadania. Não obstante, continuam a ser massivamente objeto de violência, de exploração sexual e laboral e de tráfico humano.

Para além da discriminação baseada no gênero, as mulheres migrantes - assim como os homens -, enfrentam frequentemente situações de discriminação racial, étnica e religiosa, situando-se estas em um espectro que contempla desde formas sutis de exclusão a manifestações públicas de racismo e xenofobia. Se por um lado as mulheres imigrantes procuram ativamente consagrar as conquistas obtidas em termos de direitos, ocupando os diferentes espaços da vida social em igualdade de circunstâncias, por outro continuam a ver-se confrontadas com barreiras conjunturais que as limitam nas suas escolhas e oportunidades. Marcado, do ponto de vista histórico, pelo intercâmbio com diferentes povos e culturas e pela dinâmica de mobilidade da sua população, Portugal foi palco, nas últimas décadas, de um crescente movimento de imigração, evoluindo de país de origem para igualmente país de recepção, acompanhando a tendência global da feminização da imigração.

A proliferação de estudos sobre a imigração feminina é hoje uma evidência inquestionável no domínio das Ciências Sociais e Humanas, nomeadamente em Portugal. Embora os feminismos tenham vindo a contribuir para a análise do fenômeno da imigração feminina a partir de uma leitura genderizada, é necessário aprofundar e tornar mais explícita essa leitura, articulando-a com outras que equa- cionem a influência de categorias analíticas para além do gênero nas trajetórias de vida dos imigrantes e nas próprias dinâmicas migratórias. A opressão e a exploração das mulheres é criada e reproduzida, mas também alvo de resistências, em domínios como a produção, a reprodução (que inclui a reprodução social e biológica, assim como a da força laboral), a prestação de cuidados, a socialização e a sexualidade. Porque a relação das mulheres com esses cinco domínios é contingente, econômica, política, histórica, ideológica e cultural, as questões da etnicidade, para além das de gênero e da classe social, são importantes componentes da leitura que é necessário empreender sobre as migrações femininas.

Verifica-se, contudo, que a análise do papel das mulheres nos fluxos imigratórios tem sido insuficiente por diversas razões. Em muitos aspectos, a imigração feminina continua a ser considerada como um apêndice da masculina e as mulheres a serem tomadas como pouco relevantes para o desenvolvimento das economias receptoras. Por outro lado, as mulheres movimentam-se em áreas menos visíveis e valorizadas (uma vez que a sua presença é mais significativa em contextos informais) e o seu estatuto social tende a ser menos fixo do que o dos homens, o que as faz transitar rapidamente de esposas/companheiras para trabalhadoras e vice-versa. A análise da pertença de gênero é, a par de outras, fundamental para que possam compreender as diferenças existentes no que diz respeito ao acesso aos recursos, aos serviços e aos direitos e consequências dessas diferenças para os processos de adaptação ou de exclusão nos países receptores.

Partilha-se, assim, da concepção de Mahalingam e Leu (2005), a partir da qual se defende que a intersecção entre gênero e imigração deve fazer-se, especialmente, por duas razões: primeiro, porque a perspectiva de relação entre as duas dimensões permite apreender a unicidade e a riqueza das identidades imigrantes que são construídas pela etnicidade, pela classe e pelo gênero, sob circunstâncias particulares de migração. Segundo, porque as identidades imigrantes são, muitas vezes, formadas através de um conjunto complexo de processos históricos que acentua as diferenças entre os(as) imigrantes e a cultura de recepção. 
São imperativos, por isso mesmo, estudos os quais permitam perceber a verdadeira articulação entre as políticas de imigração e de cooperação para o desenvolvimento, tendo, no centro da análise, o migrante, suas aspirações e o seu contexto de ação, como adverte Figueiredo (2005). Como faz nota a autora, "só desta forma se assegurará a máxima eficiência nas políticas a implementar e nos resultados a obter, minimizando, em simultâneo, a prossecução de interesses específicos de um ou outro país" (p.93).

Nas últimas décadas, acadêmicos e acadêmicas têm utilizado diferentes metodologias, qualitativas e quantitativas, para identificar, explorar e explicar de que modo as questões de gênero moldam as experiências de vida (Pessar, 2005). Se para além das estatísticas se quer conhecer os percursos e os seus significados, torna-se indispensável privilegiar metodologias de análise as quais tomem os indivíduos como peritos das suas experiências (Morse, 1994). No caso das mulheres imigrantes, essa questão parece fulcral. A investigação sobre imigração feminina em Portugal tem claramente privilegiado abordagens qualitativas.

A observação dos aspectos macrossociais da imigração é essencial para se captar a relação entre os Estados e os seus cidadãos estrangeiros, mas não é menos importante a auscultação dos aspectos microssociais do fenômeno, aqueles que têm a ver diretamente com as vivências dos indivíduos e a sua interpretação frente a elas. Para concluir, sublinha-se a importância de se constituir, em Portugal, uma base de dados que congregue os diferentes estudos realizados no país sobre gênero e migrações. Considera-se que esse poderia ser um importante instrumento de visibilização desse domínio, que resolveria, em larga medida, o problema da dispersão de dados com o qual Portugal ainda se confronta.

\section{Colaboradores}

Todos os autores contribuíram na concepção e desenho do estudo, análise de dados e redação final.

\section{Referências}

Abranches, M. (2007). Pertenças fechadas em espaços abertos. Estratégias de (re)construção identitária de mulheres muçulmanas em Portugal. Lisboa: ACIDI.

Assis, G. (2003). De Criciúma para o mundo: gênero, família e migração. Campos, 3, 31-49.

Assis, G. (2007). Mulheres migrantes no passado e no presente: gênero, redes sociais e migração internacional. Revista Estudos Feministas, 15(3), 745-772.

Bhavnani, K. (1997). Women's studies and its interconnection with "race", ethnicity and sexuality. In V. Robinson \& D. Richardson (Orgs.), Introducing women's studies: Feminist theory and practice ( $2^{\text {nd }}$ ed., pp.27-53) London: Macmillan.

Boyd, M. (2006). Push factors resulting in the decision for women to migrate. In UNFPA/IOM (Orgs.), Female migrants: Bridging the gaps throughout the life cycle. New York: UNFPA/IOM.

Boyle, P., \& Halfacree, K. (1999). Migration and gender in developed world. New York: Routledge.

Castles, S., \& Miller, M. (2003). The age of migration. International population movements in the modern world ( $3^{\text {rd }}$ ed.). New York: Palgrave-Macmillan.

Correia, C., \& Neves, S. (2010). Ser brasileira em Portugal: uma abordagem às representações, preconceitos e estereótipos sociais. In M. Calheiros, A. Pereira, P. Vagos, I. Direito, M. Garrido, \& D. Lopes (Orgs.), Atas do VII Simpósio Nacional de Investigação em Psicologia (pp.378-392). Recuperado em abril 3, 2013, de http:// www.actassnip2010.com/conteudos/actas/Genero_ 6.pdf

Correia, C., \& Neves, S. (2011). Ser brasileira em Portugal: uma abordagem às representações, preconceitos e estereótipos sociais. In V. Oliveira, E. Lauri, \& J. Amaral José (Orgs.), Migração: múltiplos olhares (pp.157-185). São Carlos: Pedro \& João Editores/Editora da Unir-Edufro.

Crenshaw, K. (1991). Mapping the margins: Intersectionality, identity, politics and violence against women of color. Stanford Law Review, 43, 1241-1299.

Dias, S., Rocha, C., \& Horta, R. (2009). Saúde sexual e reprodutiva de mulheres imigrantes africanas e brasileiras. Um estudo qualitativo. Lisboa: ACIDI.

Figueiredo, J. (2005). Fluxos migratórios e cooperação para o desenvolvimento. Realidades compatíveis no contexto Europeu? Porto: ACIME.

Fonseca, M., Ormond, M., Malheiros, J., Patrício, M., \& Martins, F. (2005). Reunificação familiar e imigração em Portugal. Lisboa: ACIME.

Gabaccia, D. (1992). Seeking common ground: Multidisciplinary studies of immigrant women in the United States. London: Praeger.

Garip, F., Curran, S., Shafer, S., \& Donato, K. (2006). Mapping gender and migration in sociological scholarship: 
Is it segregation or integration? International Migration Review, 40(1), 199-223.

Gill, R. (2006). Global feminism: Trends in the literature. Organization, 13, 589-598.

Gonçalves, M., \& Figueiredo, A. (2005). Mulheres imigrantes em Portugal e o mercado de trabalho: diferentes percursos, inserções laborais semelhantes. In SOS Racismo (Org.), Imigração e etnicidade: vivências e trajetórias de mulheres em Portugal (pp.63-84). Lisboa: SOS Racismo.

Hess, B., \& Ferree, M. (Orgs.) (1987). Analyzing gender: A handbook of social science research. Newbury Park: Sage.

Hollway, W. (1989). Subjectivity and method in Psychology: Gender, meaning and science. London: Sage.

King, R., \& Zontini, E. (2000). The role of gender in the South European immigration model. Papers, 60, 35-52.

Kofman, E., Sales, R., Phizacklea, A., \& Raghuram, P. (Orgs.) (2000). Gender and international migration in Europe. London: Routledge.

Lopes, L. (2007). Gravidez e seropositividade em mulheres imigrantes na região de Lisboa. Lisboa: ACIDI.

Lutz, H. (2010). Gender in the migratory process. Journal of Ethnic and Migration Studies, 36(10), 1647-1663.

Mahalingam, R., \& Leu, J. (2005). Culture, essentialism, immigration and representations of gender. Theory Psychology, 15(6), 839-860.

Malheiros, J. (2000). Circulação migratória e estratégias de inserção local das comunidades católica goesa e ismaelita. Uma interpretação a partir de Lisboa. Lusotopie, 377-398.

Manuel, H. (2007). Conhecimentos, atitudes e práticas sobre planeamento familiar de mulheres timorenses residentes em Portugal. Lisboa: ACIDI.

Miranda, J. (2009). Mulheres imigrantes em Portugal: memórias, dificuldades de integração e projetos de vida. Lisboa: ACIDI.

Monteiro, I. (2007). Ser mãe hindu: práticas e rituais relativos à maternidade e aos cuidados à criança na cultura hindu em contexto de imigração. Lisboa: ACIDI.

Morokvasic, M. (1984). Birds of passage are also women. International Migration Review, 77(1), 7-25.

Morse, J. (1994). Designing funded qualitative research. In N. Denzin \& Y. Lincoln (Orgs.), Handbook of qualitative research (pp.220-235). Thousand Oaks: Sage.

Neves, S. (2009). O silêncio mordaz das mulheres na ciência: lideranças ocultas (ou ocultadas) na Psicologia. In E. Macedo \& M. Koning (Orgs.), Reinventando lideranças: gênero, educação e poder (pp.117-139). Porto: Livpsic/FCF.
Neves, S. (2010a). Tráfico de mulheres brasileiras para fins de exploração sexual em Portugal e interseccionalidade: um estudo de caso. Psicologia, 2(24), 177-196.

Neves, S. (2010b). Sonhos traficados (escravaturas modernas?): tráfico de mulheres para fins de exploração sexual em Portugal. In S. Neves \& M. Fávero (Orgs.), Vitimologia: ciência e ativismo (pp.195-226). Coimbra: Almedina.

Neves, S. (2011). Gênero e Ciências Sociais... ou quando a Ciência também é política. In S. Neves (Org.), Gênero e Ciências Sociais (pp.15-24). Castêlo da Maia: Edições ISMAI.

Nolin, C. (2006). Transnational ruptures: Gender and forced migration. Aldershot: Ashgate.

Padilha, B. (2007). A imigrante brasileira em Portugal: considerando o gênero na análise. In J. Malheiros (Org.), Imigração brasileira em Portugal (pp.113-134). Lisboa: ACIDI.

Peixoto, J. (2004). País de emigração ou país de imigração? Mudança e continuidade no regime migratório em Portugal. Lisboa: SOCIUS. Recuperado em maio 3, 2013, de http://pascal.iseg.utl.pt/ socius/ publicacoes/wp/wp200402.pdf

Peixoto, J. (Org.) (2005). O tráfico de migrantes em Portugal. Perspectivas sociológicas, jurídicas e políticas. Lisboa: ACIDI.

Peixoto, J. P., Casaca, S. F., Figueiredo, A., Gonçalves, M., Floriano, A., Sabino, C., \& Phizacklea, A. (2006). Mulheres migrantes: percursos laborais e modos de inserção socioeconômica das imigrantes em Portugal. Lisboa: SOCIUS.

Pessar, P. (2005). Women, gender, and international migration across and beyond the Americas: Inequalities and limited empowerment. Retrieved June 6, 2013, from http://www.un.org/esa/population/meetings/ IttMigLAC/P08_PPessar.pdf

Pires, R. P. (2002). Mudanças na imigração: uma análise das estatísticas sobre a população estrangeira em Portugal, 1998-2001. Sociologia: Problemas e Práticas, 39, 151-166. Recuperado em junho 5, 2013, de http:// www.scielo.oces.mctes.pt/scielo.php?script $=$ sci_ arttext\&pid=S0873-65292002000200008\&lng=pt\& $\mathrm{nrm}=$ iso

Raposo, P., \& Togni, P. (2009). Fluxos matrimoniais transnacionais entre brasileiras e portugueses: gênero e imigração. Lisboa: ACIDI.

Santos, B., Gomes, C., Duarte, M., \& Baganha, M. I. (2008). Tráfico de mulheres em Portugal para exploração sexual. Lisboa: CIG.

Santos, C. (2007). Imagens de mulheres imigrantes na imprensa portuguesa. Análise do ano 2003. Lisboa: ACIDI.

Santos, V. (2004). O discurso oficial do Estado sobre a emigração dos anos 60 a 80 e imigração dos anos 90 à atualidade. Lisboa: ACIDI. 
Sherif, C. (1987). Bias in Psychology. In S. Harding (Org.), Feminism and methodology (pp.37-56). Milton Keynes: Open University Press.

Silva, E., Nogueira, C., \& Neves, S. (2010). (Re)conciliação dos usos do tempo: imigração, gênero e trabalho-família. Revista Psico, 41(4), 456-462. Recuperado em junho 5, 2013, de http://revistaseletronicas. pucrs. br/ojs/index.php/revistapsico/article/viewFile/8312/ 5950

Sommers, C. (1994). Who stole feminism? New York: Simon \& Schuster.

SOS Racismo. (2005). Imigração e etnicidade. Vivências e trajetórias de mulheres em Portugal. Lisboa: Autor.

Topa, J., Nogueira, C., \& Neves, S. (2010). Inclusão/exclusão das mulheres imigrantes na saúde em Portugal: reflexão à luz do feminismo crítico. Revista Psico, 41(4), 366-373. Recuperado em abril 23, 2013, de http:// revistaseletronicas.pucrs.br/revistapsico/ojs/index.php/ revistapsico/article/vie

Trovão, S., \& Ramalho, S. (2010a). Repertórios femininos em construção num contexto migratório pós-colonial. Participação cívica e política de mulheres de origem africana (Vol.I). Lisboa: ACIDI.

Trovão, S., \& Ramalho, S. (2010b). Repertórios femininos em construção num contexto migratório pós-colonial. Dinâmicas familiares, de gênero e geração (Vol.II). Lisboa: ACIDI.

United Nations Development Fund for Women. (2003). Human rights protections applicable to women migrant workers: A UNIFEM briefing paper. New York: Author. Retrieved June 5, 2013, from http://www. unifem.org/attachments/products/HRProtections Applicable2WMW_eng.p

United Nations Development Fund for Women. (2006). Empowering women migrant workers. New York: Author. Retrieved May 8, 2013, from http://www. unifem.org/attachments/gender_issues/women_ poverty_economics/WomenMigrantWorkers Brief20060607.pdf

United Nations Population Fund. (2006). State of world population 2006. A passage to hope: Women and international migration. Retrieved June 13, 2013, from http://www.unfpa.org/upload/lib_pub_file/650_ filename_sowp06-en.pdf

Wall, K., Nunes, C., \& Matias, A. R. (2005). Immigrant women In Portugal: Migration trajectories, main problems and policies. Lisboa: Instituto de Ciências Sociais.

Willis, K., \& Yeoh, B. (Orgs.) (2000). Gender and migration. Cheltenham: Edward Elgar.

Yamanaka, K., \& Piper, N. (2006). Feminised migration in east and Southeast Asia: Policies, actions and empowerment. Geneva: United Nations Research Institute for Social Development. (UNRISD Occasional Paper, 11).

Recebido: dezembro 18, 2013

Versão final: julho 16, 2014

Aprovado: setembro 9, 2014 
